\title{
Association of Rhesus Blood Group (RhD) and Toxoplasmosis in women with Miscarriage in Erbil
}

Banaz Sadik Smael; Department of Nursing, College of Nursing, Hawler Medical University, Erbil, Iraq.

(Correspondence: banaz.sadiq@nur.hmu.edu.krd)

Sadiya Abdulla Palpitany; Department of Nursing, College of Nursing, Hawler Medical University, Erbil, Iraq.

Kazhal Hassan Hamarahim; Department of Nursing, College of Nursing, Hawler Medical University, Erbil, Iraq.

\begin{abstract}
Background and objective: Toxoplasmosis has worldwide distribution and the incidence of the disease varies around the world Human blood is categorized within two main systems: $A B O$ and Rhesus factor blood group systems. The Rhesus factor protein which is the Rhesus factor gene product and a major component in the Rh blood group system carries the strongest blood group immunogen, This study aimed to estimate the sero-prevalence of toxoplasmosis and to investigate the distribution of $A B O$ and Rhesus factor blood groups among women with toxoplasma infection.

Methods: This cross-sectional study was carried out in Erbil from September 2017 to April 2018, in which 200 women with history of abortion were enrolled. Blood samples were collected and tested for anti-toxoplasma IgM antibody using direct agglutination and enzyme linked immunosorbent assay techniques.

Results: the percentages of anti-toxoplasma IgM was 33.5\% and 65 (97\%) of the seropositive women were RhD negative. Significant relationship between RhD blood group and Toxoplasma seropositive was observed while no significant relationship was found between toxoplasmosis and each ABO phenotype and demographic characteristics. Comparably, high sero-prevalence rate of anti-toxoplasma antibody was found among age group 21-40 years old (73.1\%), however, it was statistically non- significant.

Conclusion: Anti toxoplasma IgM antibodies was relatively high among women with history of abortion in Erbil and Rhesus factor positive was significant.
\end{abstract}

Keywords: Toxoplasmosis, Rh factor, ABO blood group

\section{INTRODUCTION}

Toxoplasmosis is a cosmopolitan zoonosis caused by the obligate intracellular coccidian parasite Toxoplasma gondii ( $T$. gondii) Toxoplasmosis has worldwide distribution and the incidence of the disease varies around the world [1-,3]. Major routes of $T$. gondii infection include ingestion of food or water that contaminated with oocysts shed by cats or by eating under cooked or raw meat containing tissue cysts [4]. The prevalence of infection depends on age, geographical situation, food habits as well as many epidemiological factors. The clinical spectrum of $T$. gondii infection varies from 
an asymptomatic state to sever illness $[5,6]$. Human blood is categorized within two main systems: $A B O$ blood group and RhD blood group systems. The RhD protein which is the RhD gene product and a major component in the $\mathrm{Rh}$ blood group system carries the strongest blood group immunogen, the $D$ antigen. $[7,8]$. This antigen is absent in a significant minority (about 16\%) of the population (Rh-negatives) due to $\mathrm{RhD}$ deletion or alternation. The structure homology data suggest that the RhD protein acts as an ion pump of uncertain specificity and unknown physiological role $[9,10]$. Except for the well-known but artificial role of the RhD protein in hemolytic disease of newborns, no phenotypic expression of the absence or presence of RhD on the surface of erythrocytes of a subject was known for more than sixty years. Recently, two studies on two populations of blood donors, one of conscripts [11], and the other of university students have shown that Rh-positive subjects and RhD positive heterozygotes in particular, are protected against latent toxoplasmosis-induced impairment of reaction times. A prospective cohort study performed on nearly four thousand military drivers has found that Rh-negative Toxoplasma-infected subjects have about three times higher probability of a traffic accident than Rh-negative Toxoplasma-free subjects or than Rh-positive (Toxoplasmafree or Toxoplasma-infected) subjects [12] . The importance of this study is due to high prevalence of this infection in our population especially in slaughtered houses for animals in which the sero prevalence of anti toxoplasma antibodies were high in Erbil city among animals which directly affect human [13].. The seropositive percentages of Toxoplasma among pregnant women in 2002 were showed the highest frequency $(72.4 \%)$ in Erbil city [14].
During 2015 High percentages of IgG and IgM antibodies of $t$ were found among depressive pregnant woman [15]. This study aimed to determine the seroprevalence of anti T.gondii antibodies and to explore whether Rh-positive subjects are protected against the Toxoplasma infection.

\section{METHODS}

A cross-sectional study was conducted during September 2017 until April 2018, in which 200 pregnant women who had a history of abortion and attended Maternity Teaching Hospital in Erbil city were invited to be enrolled in the study. A verbal consent was obtained from each participant through a direct interview, a structured questionnaire was completed that included demographic data (age, residency, and education). Approximately $10 \mathrm{~mL}$ of venous blood was drawn at the same time and divided into two parts, first for detecting $T$. gondii antibodies and the second was used for blood group testing. Sera were separated after centrifugation at $3000 \mathrm{rpm}$ for 10 minutes. Diagnosis of toxoplasmosis was determined by two methods enzyme linked immune absorbent (ELISA) and direct agglutination test, first direct latex agglutination test was done by utilizing Toxocell (Toxocell latex, Barcelona, Spain); this technique was used for direct detection of T.gondii antibodies according to the manufacturer's instructions. the detection of IgM anti- $T$. gondii was done by ELISA Biokit, Toxo IgM (Biomieux, Spain) with cut-off value $\geq 0.65$. The $A B O$ phenotypes then identified by the standard test tube hemagglutination using commercial monoclonal anti-sera anti-A, anti-B and anti-A,B for direct typing and standard red blood cells $A 1$ and $B$ for reverse typing (Fresenius Kabi, Brazil). 
Research proposal was approved by Scientific Committee of College of Nursing at Hawler Medical University. Informed consent was taken from participants of the study after explaining the purposes of the study. The data was analyzed by using percentages and frequency also the $X^{2}$ test for significance differences. The probability level of $\leq 0.05$ is accepted as statistically significant. Statistical analyses are carried out by SPSS software (version 20; SPSS, Inc., USA).

\section{RESULTS}

Table 1 shows the demographic characteristics of the 200 women with a history of abortion. According to age, which was divided into three groups, a higher percentage of age in this study sample was found among age group 21-40 years old (79\%), while lower percentage was among 41 and over (16\%). Most lived in a rural area (57.5\%). Regarding educational level, most were non-educated $(52.5 \%)$, and the remaining were educated (47.5\%).

Table 1: Demographic characteristics of the study sample:

\begin{tabular}{ll}
\hline Demographic characteristics & $F(\%)$ \\
\hline Age group & \\
$20 \&$ under & $26(13)$ \\
$21-40$ & $158(79)$ \\
$41 \&$ over & $16(8)$ \\
Residence & \\
Urban & \\
Rural & $85(42.5)$ \\
Educational status & $115(57.5)$ \\
Educated & \\
Non- educated & $95(47.5)$ \\
\hline
\end{tabular}

The frequencies of the four $A B O$ blood group phenotypes were $20.5 \%$ for group $A$, $25 \%$ for group $B, 9 \%$ for group $A B$, and $45.5 \%$ for group $O$, and $66.5 \%$ of the cases were $\mathrm{Rh}$ positive and $33.5 \%$ of them were $\mathrm{Rh}$ negative. Of the participants, 33.5\% presented positive anti toxoplasma antibody and $66.5 \%$ had negative serological results for anti-T. gondii antibodies as shown in table 2 .

Table 2: Frequencies of the $A B O$ blood group phenotypes in pregnant women with positive and negative serology for anti-Toxoplasma gondii antibodies

\begin{tabular}{lc}
\hline Blood group & $F(\%)$ \\
\hline A & $41(20.5)$ \\
$B$ & $50(25)$ \\
$A B$ & $18(9)$ \\
O & $91(45.5)$ \\
Rh factor & \\
Positive & $133(66.5)$ \\
Negative & $67(33.5)$ \\
Toxoplasmosis & \\
Positive & $67(33.5)$ \\
Negative & $133(66.5)$ \\
\hline
\end{tabular}

Table (3), reveals the association of sociodemographic data and maternal toxoplasmosis. Demographic characteristics those were not significantly associated with toxoplasmosis $(P>0.05)$ in this group were: age group, residence area and educational level with ( $p$-value $=0.261$, 0.644 and 0.958 ) respectively. However, while not significant, a high sero prevalence rate of toxoplasmosis was among the age group of 21 to 40 years old (73.1\%), with the majority of them being from rural area (55.2\%) and being educated (47.8\%). The lowest percentage of infection was among age group 41 and over (11.9\%). The overall seropositive prevalence rate is (33.5\%). 
Table 3: Distribution of age, residence, educational status and anti-toxoplasma IgM antibody among pregnant women

\begin{tabular}{lcccc}
\hline Demographic data & $\begin{array}{c}\text { Positive } \\
\text { toxoplasmosis F (\%) }\end{array}$ & $\begin{array}{c}\text { Negative } \\
\text { Toxoplasmosis F (\%) }\end{array}$ & Total F (\%) & P_Value \\
\hline Age group & $10(14.9)$ & $16(12.1)$ & $26(13)$ & 0.2617 \\
\hline $\mathbf{2 0}$ & $49(73.1)$ & $109(84.9)$ & $158(79)$ & \\
$\mathbf{2 1 - 4 0}$ & $8(11.9)$ & $8(6.01)$ & $16(8)$ & \\
$\mathbf{2 4 1}$ & $67(33.5)$ & $133(66.5)$ & $200(100)$ & \\
Total & & & & \\
Residence & $30(44.8)$ & $55(41.4)$ & $85(42.5)$ & 0.6440 \\
Urban & $37(55.2)$ & $78(58.6)$ & $115(57.5)$ & \\
Rural & & & & \\
Educational status & $32(47.8)$ & $63(47.4)$ & $95(47.5)$ & 0.9581 \\
Educated & $35(47.4)$ & $70(52.6)$ & $105(52.5)$ & \\
Non educated & $67(33.5)$ & $133(66.5)$ & $200(100)$ & \\
Total & & & & \\
\hline
\end{tabular}

The frequencies of $A B O$ blood group phenotypes, in respect to results of the serological test (positive and negative) for anti-T. gondii antibodies as listed in Table (4) do not demonstrate statistically significant differences ( $p$-value $=0.134$ ) while there was highly significant relationship between RhD blood group and Toxoplasma infection ( $p$-value $0.0001)$.

Table 4: Association of ABO blood group, Rh factor and toxoplasma infection.

\begin{tabular}{|c|c|c|c|c|}
\hline & $\begin{array}{l}\text { Positive toxoplasmosis } \\
\text { F (\%) }\end{array}$ & $\begin{array}{l}\text { Negative toxoplasmosis } \\
\text { F (\%) }\end{array}$ & $\begin{array}{l}\text { Total } \\
\text { F (\%) }\end{array}$ & P_Value \\
\hline \multicolumn{5}{|c|}{ ABO blood group } \\
\hline A & $20(29.9)$ & $21(15.8)$ & $41(20.5)$ & 0.134 \\
\hline B & $14(20.9)$ & $36(27.1)$ & $50(25)$ & \\
\hline$A B$ & $6(9)$ & $12(9)$ & $18(9)$ & \\
\hline 0 & $27(40.3)$ & $64(48.1)$ & $91(45.5)$ & \\
\hline Total & $67(33.5)$ & $133(66.5)$ & $200(100)$ & \\
\hline \multicolumn{5}{|l|}{ Rh factor } \\
\hline Positive & $2(3)$ & $131(98.5)$ & $133(66.5)$ & 0.0001 \\
\hline Negative & 65(97) & $3(1.5)$ & $67(33.5)$ & \\
\hline Total & $67(33.5)$ & $133(66.5)$ & $200(100)$ & \\
\hline
\end{tabular}




\section{DISCUSSION}

The aim of this study was to determine the sero prevalence of anti-Toxoplasma gondii antibodies and to explore whether Rhpositive subjects are protected against the toxoplasma infection. Our result reveals overall sero prevalence rate toxoplasmosis IgM antibodies among aborted women (33.5\%), ELISA result is similar to those studies done in Al- Hawiji and Al- Baiji districts in Iraq by Al- Jebouri et al in 2013and those done in Qadisyiyah province in Iraq by Hadi et al in 2016, they found high sero prevalence rate of toxoplasmosis among aborted women [20, 21]. These similarities in high sero prevalence rate of toxoplasmosis in different women in different area depend on several factors like: environmental effects, traditional habits, economic status, and hygiene condition in these areas. Also high rate of infection was found among age group 20-40 years old which is in accordance to those reported by Hung et al (2007), this might be due to the fact that this rang of age is child bearing age and usually women became more susceptible and symptoms more obviously appear during pregnancy [22]. No significant relation was found between age group and sero prevalence of Toxoplasmosis, this result compatible with those reported in United States by Jones et al in 2001 [23]., but it's different from those done in Iran by Ahmed et al in 2014 who found A significant linear trend of increasing overall sero prevalence of Toxoplasmosis by age [24]. The present results do not demonstrate any association between evidence of infection by $T$. gondii and the $A B O$ blood group system and, thus, does not agree with those studies that proposed that the $B$ antigen, expressed in $B$ and $A B$ blood groups, acts as a potential receptor for this parasite in the gastrointestinal tract [16-17]. On the other hand, the results agreed with investigations of blood donors in Tanzania and of pregnant French women, which did not report any association between this system and infection by $T$. gondii $[8,19]$. The disagreement among these results and other studies may result from several factors. It is possible that the $B$ antigen exerts a small influence on the adherence of $\mathrm{T}$. gondii to the gastrointestinal mucosa and its contribution is obscured by the high prevalence of infection by these parasites in our population. Moreover, the use of only female patients in this study might not be sufficient to reveal possible influences of gender in the association of the $A B O$ blood group system with infection by $T$. gondii [19].

The present results was also indicated that RhD phenotype modulates the responses of the body to anti toxoplasma antibody this result agree with those reported by Fleeger et al in 2009 [12] but its differ from those done in America by Parnell in 2014 [25] However, the results of previous studies and current knowledge about localization and probable function of $\mathrm{Rh}$ proteins suggest that RhD proteins that act as ion pumps, coded for at the RH locus and localized on the erythrocyte membrane, are involved in the regulation of ion balance in some critical compartment of nerve or muscle tissue. such regulation could be important especially in the subjects handicapped by the presence of Toxoplasma cysts in nerve and muscle tissues $[10,11]$.

\section{CONCLUSIONS}

Anti-toxoplasma IgM antibodies were relatively high among women with a history of abortion in Erbil. ABO blood groups distribution was not significantly 
associated with toxoplasmosis, however significant sero-prevalence rate of toxoplasmosis was observed among women who were negative for RhD antigen Screening for toxoplasmosis in women prior to pregnancy is an insisted demand in order to prevent abnormal pregnancy termination.

\section{CONFLICT OF INTEREST}

The Authors report no conflict of interest

\section{ACKNOWLEDGEMENT}

The author would like to thank all participants who participated in conducting the study.

\section{REFERENCES}

[1] Dubey JP, Lindsay DS, Speer CA . Structures of Toxoplasma gondii tachyzoites, bradyzoites and Sporozoites and biology and development of. tissue cysts. Clinical Microbiology Review 1998.(11):267-299.

[2] Hill DE, Chirukandoth S and Dubey JP . Biology and epidemiology of Toxoplasma gondii in man and animals. Animal Health Research Review, 2005 (6):41-61.

[3] Dubey JP. Toxoplasmosis of animals and humans. Second edition .Boca .Raton, Florida CRC press.

[4] Dawson D . Foodborne protozoan parasites. Internal Journal of Food Microbiology. 2005 (103):207- 227.

[5] Walker M and Zunt JR .Parasitic central nervous system infections in immunocompromised hosts. Clinical ilnfectious Disease. 2005. (40):1005-1015.

[6] Balasundaram MB, Andavar $\mathrm{R}$, Palaniswamy $\mathrm{M}$, Venkatapathy $\mathrm{N}$. outbreak of acquired ocular toxoplasmosis involving 248 patients. Archive of Ophthalmology, 2010(128):28-32.

[7] Flegel W.A. Molecular genetics of $\mathrm{RH}$ and its clinical application. Transfusion Clinical Biology 2006 (13): 4-12.
[8] Carritt B., Kemp T.J., Poulter M. Evolution of the human RH (rhesus) blood group genes: a 50 year old prediction (partially) fulfilled. Human Molecular Genetic. 1997 (6): 843-850.

[9] Biver S., Scohy S., Szpirer J., Szpirer C., Andre B., Marini A.M. Physiological role of the putative ammonium transporter RhCG in the mouse. Transfusion Clinical Biology. 2006 ,(13): 167-168.

[10] Kustu S., Inwood W. Biological gas channels for NH3 and CO2: evidence that Rh (Rhesus) proteins are $\mathrm{CO} 2$ channels. Transfusion Clinical Biology. 2006, (13): 103-110.

[11] Novotná M., Havlíček J., Smith A.P., Kolbeková P., Skallová A., Klose J.et al Toxoplasma and reaction time: role of toxoplasmosis in the origin, preservation and geographical distribution of $\mathrm{Rh}$ blood group polymorphism. Parasitology. 2008, (135): 1253-1261.

[12] Flegr J., Klose J., Novotná M., Berenreitterová M., Havlíče J. Increased incidence of traffic accidents in Toxoplasma infected military drivers and protective effect $\mathrm{RhD}$ molecule revealed by a large-scale prospective cohort study. BMC Infectious Disease. 2009. (9): e72.

[13] Kader JM, Seroprevalence of Toxoplasma gondi in some meat producing animals in Erbil city. MSc thesis. College of Medicine. Hawler Medical University. 2010.

[14] Bakre HM, Evaluation of immunocapture ELISA and other testes for diagnosing Toxoplasmosis. MSc thesis. College of Medicine. Hawler Medical University. 2002.

[15] Mohammed AK, Possible role of Toxoplasma gondi infection, cytokines and inflammatory markers in patients with major depressive disorders. MSc thesis. College of Medicine. Hawler Medical University. 2015. 
[16] Kolbekova P, Kourbatova E, Novotna M, Kodym P, Flegr J. New and old riskfactors for Toxoplasma gondii infection: prospective cross-sectional study among military personnel in the Czech Republic. Clinical Microbiology Infection. 2007;13 (10):12-7.

[17] Midtvedt T, Vaage L. Relationship between Toxoplasma gondii antibodies and blood group. European Journal of Clinical Microbiology Infectious Disease. 1989;8 (6):575-6.

[18] Gill HS. Occurrence of Toxoplasma gondii antibodies in Tanzanian blood donors. East African Medical Journal. 1985;62 (8):585-8.

[19] Lecolier B, Grynberg H, Freund M. Absence of relationship between Toxoplasma gondii antibodies and blood group in pregnant women in France. European Journal of Clinical Microbiology Infectious Disease. 1990;9(2):152-3.

[20] Al-Jebouri M, Al-Janabi M, Ismail H. The prevalence of Toxoplasmosis among female patient in Al-Hawija and Al- Baiji Districts in Iraq. Open Journal of Epidemiology.2013;3(38):85-88.

[21] Hadi HS, Kadhim RA, Al-Mammori RT. Seroepidemiological aspects for Toxoplasma gondii infection in women of qadisyiyah province, Iraq. International Journal of Pharmacology and Technelogy Research.2016;9(11):252-59.

[22] Hung CC, Fan CK, Su KE, Sung FC, Chiou $A Y, G i l$, et al. Serological screening and toxoplasmosis exposure factors among pregnant women in the Democratis Republic of Sao Tome and Principe. Journal of Transactions of the Royal Society Tropical Medical Hygiene. 2007; 101 (2):97-103.

[23] Jones JL, Kruszan MD, Wilson M, Mcquillan G, Navin T, McAuley JB. Toxoplasma gondii Infection in the United states: seroprevalence and risk factors. American Journal of Epidemiology. 2001154 (4):357-65.
[24] Ahmed D, Shahabeddin S, Mohsen A, Azadeh M, Ehsan A, Azar S, et al Seroprevalence of Toxoplasma gondii in the Iranian general population: A systematic review and meta-analysis ,Acta Tropica. 2014; (137):185-194 .

[25] Parnell L L. Examination of Possible Protective Effect of Rhesus D Positive Blood Factor on Toxoplasma-related Depressive Symptoms in Pregnancy. PhD. College of Nursing University of South Florida. 2014. 